\title{
THE LAPTOP SPARE PARTS STUDYING UNDER CONSIDERING USERS' REPAIR WILLINGNESS
}

\author{
Lu, X.-C. \& Wang, H.-N. \\ School of Economics and Management, Beijing Jiaotong University, Beijing, China \\ E-Mail: Xclu@bjtu.edu.cn
}

\begin{abstract}
With the development of science and technology, laptop becomes very popular. Laptop manufacturing firms are concerning how much spare parts they shall prepare to meet the demand of repairing. The quantities of spare parts are not only related to laptop life time, but also concern with users' repair willingness. We propose an approach to calculate the repair probability of laptop parts combined Poisson Process with users' repair willingness. In this study, the users' repair willingness relates laptop parts failure frequency. The new approach's verification is carried on by simulation. The significant test results show that simulation data fit theoretical value very well. By survey data and simulation result, we find that after four times broken for a laptop, a user will give up repairing it. The calculation result of new approach shows that spare parts quantities are entirely lower than traditional theory. From this point, if laptop manufacturers know their each parts lifetime, with the help of this paper, they can cut down their spare parts and save their service costs reasonable than before. (Received, processed and accepted by the Chinese Representative Office.)
\end{abstract}

Key Words: $\quad$ Laptop Spare Parts, Users’ Repair Willingness, Poisson Process

\section{INTRODUCTION}

The laptops are necessary electrics for many people. When someone's laptop is broken down, what he will do? Buy a new laptop or send to repair it? In our life, we find frequently when a laptop is out of working, a person will not repair it at once. He may buy a new one instead of repairing it if this laptop has been broken many times. With the computer manufacturing technology development, this phenomenon becomes more common. So manufactures shouldn't prepare their spare parts as usual. The users' real repairing demands are less than before. How to estimate the quantities of spare parts under considering users' repairing willingness is the core issue of this paper.

Many people have studied the electric products spare parts from the life time theory. The users' repairing willingness is seldom discussed in their papers. In this paper, we have studied the laptops lifetime firstly, and then we have investigated the users' repairing willingness by survey data. After that, the approach of spare parts calculation based on users' repairing willingness is put forward. Finally, simulation model is built to verify the approach, and significance test has been applied to make sure researching work is tenable.

\section{LITERATURE REVIEW}

There is a lot of researching on spare parts management. Increasingly, scholars have found out many different ways to do the investigation.

Some researchers have investigated spare parts issues from inventory problem. Al-Hawari et al. (2013) studied the great effect of on-hand inventory and percentage of satisfied customers on the supply chain management and got the different inventory policies about high/low demand rate through simulation model [1]. Mostly inventory policies are based on demand forecasting, Buchmeister et al. (2012) put forward a three-stage supply chain's inventory policy based on time series of the market demand data [2]. Huiskonen 
(2001) put forward 16 types of spare parts and the different operation strategies had been custom-made for the different types of services in service of spare parts supply chain [3]. Wong et al. (2005) studied the spare parts transportation and inventory problems in a multi-hub system [4]. Cheng and Prabhu (2012) studied the service oriented from two kinds of dimensions and evaluated the technology complexity and system [5]. Jin and Tian (2012) mainly researched the non-stationary demand of repairable inventory, which is performance based logistic and built a dynamic and integrated service supply chain [6].

Through the process of classifying the spare parts, Park and Lee (2011), Bosnjakovic (2010) obtained two different multicriteria inventory models for the parts inventory system [7, 8]. Levner et al. (2011) tried to use the Wagner-Whitin property to solve the spare-part inventory management problem and it had been proved as practical [9]. Rausch and Liao (2010), Wang (2012) and Basten et al. (2012) researched the joint optimization between spare parts inventory and repair analysis [10-12]. Selcuk and Agrali (2013) studied the reliability and inventory problems and developed several models to minimize the sum of holding and emergency shipment costs subject to a limited reliability improvement budget and a target service level [13].

Godoy et al. (2013) described a graphic technique, which considers a rule for decision based on both condition-based reliability function and a stochastic/fixed lead time, for the Condition Managed Critical Spares and it was useful to spare parts management [14]. Louit et al. (2010) present a dynamic control system for the service rate in an $M / M / 1$ queuing system, which is based on the mobile equipment' normal and expedited repair rates [15]. Bacchetti and Saccani (2011) summarized the difference between research in and practicing in spare parts management, and then put forward four main directions for further research [16]. A stochastic model often used in the research of spare parts inventory, Wang (2011), Van Horenbeek et al. (2013) and Liu et al. (2013) developed a stochastic simulation model to investigate the spare parts inventory $[11,17,18]$. Sahba and Balcioglu (2011) investigated the impact of transportation delays on the through the method of multiple finite-population queueing systems and obtained the steady-state distribution of components and the cost of the system [19].

Kleber et al. (2012) studied the spare parts inventory through the view of reverse logistics, and put forward a MILP formulation [20]. Syntetos et al. (2012) studied the issue of demand distributional assumptions for spare parts management, and used the real data to evidence the investigation [21]. Sahba et al. (2013) established two models for first-come first-served policy and a static priority rule respectively and draw the conclusion that a hybrid priority policy is better than a hybrid first-come first-served policy [22].

In the service of spare parts inventory management, service spare parts' demand prediction is an important part. It is of great significance for service spare parts inventory management, as well as the most difficult part. Zhou and Viswanathan (2011) addressed the problem of forecasting and found out a new bootstrapping method with the parametric methods [23]. Lynch et al. (2013) used genetic algorithm to obtain optimal spares and preventive maintenance frequencies, and a simulation model was built using software Anylogic [24]. Eaves and Kingsman (2004) put forward a modified Croston model for commonwealth royal air force aircraft spare parts demand prediction [25]. Willemain et al. (2004) discussed a new approach-Bootstrop method for the service parts inventory forecasting intermittent demand's prediction [26]. Huang et al. (2011) set up a stochastic inventory model, through the demand forecasting and classification of spare parts, chose inventory policies and determined basic inventory parameters to establishment the demand forecasting model [27].

Because of the complexity of the service parts supply chain structure, the traditional approach does not fully take into account the relationship between the various determinants. 
Therefore, Li and Kuo (2008) introduced neural network technology into inventory model to predict the demand for spare parts [28]. In order to meet all the time based service level limited and cost constraints limited, Kutanoglu and Mahajan (2009) developed implicit enumeration method to determine the optimal basic local warehouse inventory levels [29]. Gao and Hao (2012) presented a classification model and built up a three level hierarchy based on these five key criterions [30]. Yang et al. (2013) assessed the effect of pipeline stock flexibility in one or two-echelon inventory models where the lateral transhipment time is not negligible and it showed that the approximations perform well in terms of both system performance and costs [31].

\section{THE LIFETIME OF LAPTOP}

The bibliography shows that the lifetime of electric device obeys exponential distribution, and the failure process of electric device is Poisson Process [32].

Now, we discuss the lifetime of laptops.

\subsection{The failure probability of laptop}

For a batch of laptops, we note the failure process $\{N(t), t \geq 0\}$ as a Poisson Process having failure rate $\lambda, \lambda>0 . N(t)$ satisfies:

(i) $N(0)=0$;

(ii) The process has independent increments;

(iii) The number of events in any interval of length $t$ is Poisson distributed with mean $\lambda t$. That is, for all $s, t \geq 0$

$$
P\{N(t+s)-N(s)=n\}=e^{-\lambda t} \frac{(\lambda t)^{n}}{n !} \quad n=0,1,2 \ldots
$$

Eq. (1) is the definition of the Poisson Process.

We note $T_{n}, n=1,2, \ldots$, as the interval time of laptops failure event. $T_{n}$ are independent identically distributed exponential random variables. $S_{n}$ is noted as the duration of a laptop $n^{\text {th }}$ failure event, $S_{n}$ can be calculated as:

$$
S_{n}=\sum_{1}^{n} T_{i} \quad n \geq 1
$$

The probability density of $S_{n}$ is given by $f_{S n}$, shown as eq. (2).

$$
f_{S_{n}}(t)=\lambda e^{-\lambda t} \frac{(\lambda t)^{n-1}}{(n-1) !} \quad t \geq 0
$$

Eq. (2) told us that the $n^{\text {th }}$ failure event will occur prior to or at time $t$ if and only if the number of laptops failure events occurring by time $t$ is at least $n$. That is:

Hence:

$$
N(t) \geq n \quad \Leftrightarrow \quad S_{n} \leq t
$$

$$
F_{S_{n}}(t)=P\left\{S_{n} \leq t\right\}=P\{N(t) \geq n\}=P\left\{S_{n} \leq t, N(t) \geq n\right\}=1-\sum_{k=0}^{n-1} e^{-\lambda t} \frac{(\lambda t)^{k}}{k !}
$$

So, the failure probability in $(t-s, t]$ is:

$$
\begin{aligned}
& P\left\{t-s<S_{n} \leq t, N(t) \geq n\right\} \\
& =P\left\{S_{n} \leq t, N(t) \geq n\right\}-P\left\{S_{n} \leq t-s, N(t) \geq n\right\} \\
& =e^{-\lambda t} \cdot \sum_{k=0}^{n-1} \frac{\lambda^{k}}{k !}\left[e^{\lambda}(t-s)^{k}-t^{k}\right]
\end{aligned}
$$




\subsection{The failure probability compound of different laptop parts}

We will discuss the failure probability of laptop parts. We know that a laptop is constituted by CPU, main board, memory cards, hard disk and other parts. These parts have different lifetime. Some parts are broken easier, and some parts are durable.

$$
\begin{gathered}
\left\{\begin{array}{l}
P\left\{N_{1}(t) \mid N(t)\right\}=\frac{\lambda_{1}}{\sum \lambda} \\
P\left\{N_{2}(t) \mid N(t)\right\}=\frac{\lambda_{2}}{\sum \lambda} \\
P\left\{N_{3}(t) \mid N(t)\right\}=\frac{\lambda_{3}}{\sum \lambda} \\
\sum \lambda=\lambda_{1}+\lambda_{2}+\lambda_{3}
\end{array}\right. \\
\left\{\begin{array}{l}
P_{N_{1}}\left\{t-s<S_{n} \leq t, N(t)=n\right\}=\lambda_{1} e^{-\sum \lambda t} \cdot \sum_{k=0}^{n-1} \frac{\left(\sum \lambda\right)^{k-1}}{k !}\left[e^{\sum \lambda}(t-s)^{k}-t^{k}\right] \\
P_{N_{2}}\left\{t-s<S_{n} \leq t, N(t)=n\right\}=\lambda_{2} e^{-\sum \lambda t} \cdot \sum_{k=0}^{n-1} \frac{\left(\sum \lambda\right)^{k-1}}{k !}\left[e^{\sum \lambda}(t-s)^{k}-t^{k}\right] \\
P_{N_{3}}\left\{t-s<S_{n} \leq t, N(t)=n\right\}=\lambda_{3} e^{-\sum \lambda t} \cdot \sum_{k=0}^{n-1} \frac{\left(\sum \lambda\right)^{k-1}}{k !}\left[e^{\sum \lambda}(t-s)^{k}-t^{k}\right] \\
\sum \lambda=\lambda_{1}+\lambda_{2}+\lambda_{3}
\end{array}\right.
\end{gathered}
$$

We assume that there are 3 kinds of main parts in a laptop. They are Part 1, Part 2 and Part 3. We also assume the broken rates of these parts are $\lambda_{1}, \lambda_{2}, \lambda_{3}$. From 2.1, we know that the failure process of electrics is Poisson process. We note 3 parts failure process with $N_{1}(t)$, $N_{2}(t), N_{3}(t)$. So $N(t)=N_{1}(t)+N_{2}(t)+N_{3}(t)$ is a compound Poisson process. The compound failure rate $\lambda$ should be: $\Sigma \lambda=\lambda_{1}+\lambda_{2}+\lambda_{3}$. For this compound Poisson process, it has this property as eq. (5).

From eqs. (4) and (5), we can get the failure probability of every parts in $(t-s, t]$ which total failure events is at least $n$. It is in eq. (6).

\subsection{The repair probability of laptop parts with users' considering failure frequency}

When a laptop broke, if a user will send it to repair or not, is decided by his willingness. We note $r_{j}$ as a user's repair willingness after a laptop having been failed $j$ times.

Table I is the survey data of repair willingness related to failure frequency. From Table I, we know that after 4 times broken, only $3.4 \%$ of users will send their laptops to repair.

Table I: The user's repair willingness related to failure frequency.

\begin{tabular}{|c|c|c|}
\hline Failure frequency $\boldsymbol{j}$ & Repair willingness & $\boldsymbol{r}_{\boldsymbol{j}}$ \\
\hline 1 & $100.0 \%$ & $r_{1}$ \\
\hline 2 & $38.6 \%$ & $r_{2}$ \\
\hline 3 & $18.2 \%$ & $r_{3}$ \\
\hline 4 & $3.4 \%$ & $r_{4}$ \\
\hline
\end{tabular}




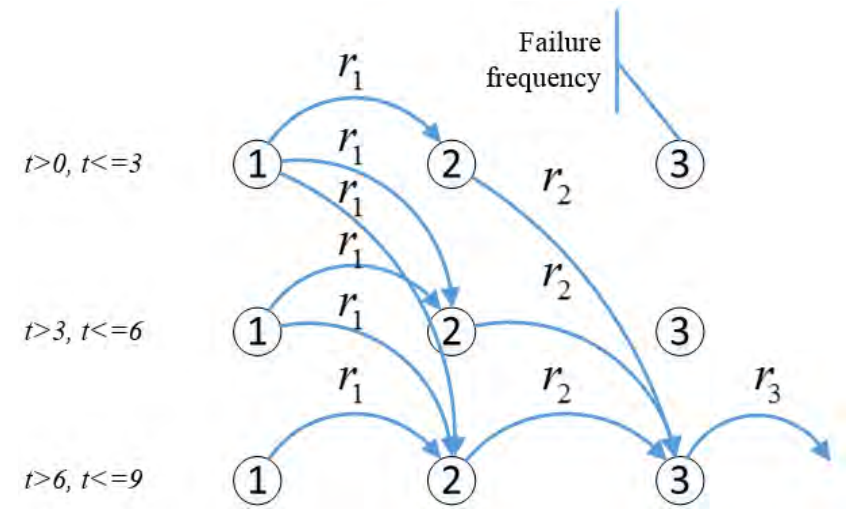

Figure 1: The repairing willingness transition probability of failure frequency (Broken times $n=3$ ).

$$
\left\{\begin{array}{l}
P_{1}\left\{t-s<S_{n} \leq t, N(t)\right\}=\prod_{j=1}^{n} r_{j} \cdot P_{N_{1}}\left\{t-s<S_{n} \leq t, N(t)\right\}=\lambda_{1} e^{-\sum \lambda t} \cdot \prod_{j=1}^{n} r_{j} \cdot \sum_{k=0}^{n-1} \frac{\left(\sum \lambda\right)^{k-1}}{k !}\left[e^{\sum \lambda}(t-s)^{k}-t^{k}\right] \\
P_{2}\left\{t-s<S_{n} \leq t, N(t)\right\}=\lambda_{2} e^{-\sum \lambda t} \cdot \prod_{j=1}^{n} r_{j} \cdot \sum_{k=0}^{n-1} \frac{\left(\sum \lambda\right)^{k-1}}{k !}\left[e^{\sum \lambda}(t-s)^{k}-t^{k}\right] \\
P_{3}\left\{t-s<S_{n} \leq t, N(t)\right\}=\lambda_{3} e^{-\sum \lambda t} \cdot \prod_{j=1}^{n} r_{j} \cdot \sum_{k=0}^{n-1} \frac{\left(\sum \lambda\right)^{k-1}}{k !}\left[e^{\sum \lambda}(t-s)^{k}-t^{k}\right]
\end{array}\right.
$$

If a laptop failed in $(t-s, t)$, and it had broken $n$ times, the transition probability of users repair willingness is $r_{1}, r_{2}, \ldots, r_{n}$, i.e. the transition probability is $\Pi_{1}^{n} r_{j}$. Fig. 1 is an example when a laptop is broken during the $6^{\text {th }}$ month to the $9^{\text {th }}$ month and it is the $3^{\text {rd }}$ times broken. The probability of this laptop sent to repair always is $r_{1} r_{2} r_{3}$, no matter what condition is.

So consider eq. (6), we can get laptop parts repairing probability under certain repairing willingness. We note repair probability for Part 1, Part 2, Part 3 as $P_{1}\left\{t-s<S_{n} \leq t, N(t)\right\}$, $P_{2}\left\{t-s<S_{n} \leq t, N(t)\right\}, P_{3}\left\{t-s<S_{n} \leq t, N(t)\right\}$. They should be as eq. (7). Let:

$$
Z(j, n)=e^{-\sum \lambda t} \cdot \prod_{j=1}^{n} r_{j} \cdot \sum_{k=0}^{n-1} \frac{\left(\sum \lambda\right)^{k-1}}{k !}\left[e^{\sum \lambda}(t-s)^{k}-t^{k}\right]
$$

Eq. (7) could be rewritten as eq. (8).

$$
\left\{\begin{array}{l}
P_{1}\left\{t-s<S_{n} \leq t, N(t)\right\}=\lambda_{1} Z(j, n) \\
P_{2}\left\{t-s<S_{n} \leq t, N(t)\right\}=\lambda_{2} Z(j, n) \\
P_{3}\left\{t-s<S_{n} \leq t, N(t)\right\}=\lambda_{3} Z(j, n) \\
Z(j, n)=e^{-\sum \lambda t} \cdot \prod_{j=1}^{n} r_{j} \cdot \sum_{k=0}^{n-1} \frac{\left(\sum \lambda\right)^{k-1}}{k !}\left[e^{\left.\sum^{\lambda}(t-s)^{k}-t^{k}\right]}\right.
\end{array}\right.
$$

By eq. (8), we can calculate spare parts of laptops during the time $(t-s, t)$.

\section{MODELLING VERIFICATION}

In order to verify eq. (6) (the failure parts model without considering users' repair willingness), eq. (8) (repairing willingness is considered), we take simulation modelling to verify two equations.

\subsection{The failure parts model verification}

1) The quantities of failure parts calculation

In this section, we will verify eq. (6) by example data. 
Firstly, we assume totally there are 1000 laptops. Secondly, we assume that there are three kinds of parts in a laptop and we assume these parts failure rate are: $\lambda_{1}=0.025$ per month, $\lambda_{2}=0.020$ per month, and $\lambda_{3}=0.0167$ per month. That is to say their lifetimes are: 40 months, 50 months and 60 months.

According eq. (1), we can get three parts overall failure probability distribution. It is shown as Table II. In this table, we separate time $t$ into different stages $j$ with every 3 months.

According eq. (6) and Table II, we can get three parts failure probability separately when time $t$ is between $(27,30$ ] (which stage $j=9)$. It is shown in Table III.

Table II: Failure probability distribution of a laptop.

\begin{tabular}{|c|c|c|c|c|c|c|c|c|}
\hline \multirow{2}{*}{ Time $\boldsymbol{t}$ (month) } & Stages & \multicolumn{8}{|c|}{ Failure frequency $\boldsymbol{n}$} \\
\cline { 2 - 10 } & $\boldsymbol{j}$ & $\mathbf{1}$ & $\mathbf{2}$ & $\mathbf{3}$ & $\mathbf{4}$ & $\mathbf{5}$ & $\mathbf{6}$ & $\mathbf{7}$ \\
\hline 3 & 1 & 0.1689 & 0.0151 & 0.0009 & 0.0000 & 0.0000 & 0.0000 & 0.0000 \\
\hline 6 & 2 & 0.3093 & 0.0537 & 0.0064 & 0.0006 & 0.0000 & 0.0000 & 0.0000 \\
\hline 9 & 3 & 0.4259 & 0.1073 & 0.0189 & 0.0025 & 0.0003 & 0.0000 & 0.0000 \\
\hline$\ldots$ & $\ldots$ & $\ldots$ & $\ldots$ & $\ldots$ & $\ldots$ & $\ldots$ & $\ldots$ & $\ldots$ \\
\hline 27 & 9 & 0.8108 & 0.4958 & 0.2336 & 0.0880 & 0.0274 & 0.0073 & 0.0017 \\
\hline$\ldots$ & $\ldots$ & $\ldots$ & $\ldots$ & $\ldots$ & $\ldots$ & $\ldots$ & $\ldots$ & $\ldots$ \\
\hline 69 & 23 & 0.9858 & 0.9254 & 0.7969 & 0.6147 & 0.4209 & 0.2559 & 0.1389 \\
\hline
\end{tabular}

Note: In this table, $\lambda=\lambda_{1}+\lambda_{2}+\lambda_{3}=0.06167$.

According the first assumption, the quantities of laptop is 1000 pcs, and by Table III, we can get failure quantities of three parts, shown as Table IV.

Table III: Three kinds of spare parts failure probability.

\begin{tabular}{|c|c|c|c|}
\hline Failure frequency $\boldsymbol{n}$ & Part1 & Part2 & Part3 \\
\hline 1 & 0.012954 & 0.010363 & 0.008636 \\
\hline 2 & 0.022730 & 0.018184 & 0.015153 \\
\hline 3 & 0.019960 & 0.015968 & 0.013307 \\
\hline 4 & 0.011696 & 0.009357 & 0.007797 \\
\hline 5 & 0.005145 & 0.004116 & 0.003430 \\
\hline 6 & 0.001812 & 0.001450 & 0.001208 \\
\hline
\end{tabular}

Note: This table only gives out three parts failure probability when time $t$ is $30 \geq t>27$.

Table IV: Failure quantities of three parts $(30 \geq t>27)$.

\begin{tabular}{|c|c|c|c|}
\hline \multirow{2}{*}{ Failure frequency $(\boldsymbol{n})$} & \multicolumn{3}{|c|}{ Quantities of failure parts } \\
\cline { 2 - 4 } & Part 1 (pcs) & Part 2 (pcs) & Part 3 (pcs) \\
\hline 1 & 12.95 & 10.36 & 8.64 \\
\hline 2 & 22.73 & 18.18 & 15.15 \\
\hline 3 & 19.96 & 15.97 & 13.31 \\
\hline 4 & 11.70 & 9.36 & 7.80 \\
\hline 5 & 5.14 & 4.12 & 3.43 \\
\hline 6 & 1.81 & 1.45 & 1.21 \\
\hline
\end{tabular}

2) The failure parts quantities simulation

In order to verify the failure eq. (6), we built an Agent based simulation model. The state chart about simulation model is shown as Fig. 4. 
In this simulation model, when a laptop part is broken, a user will make a decision to repair it. In Fig. 4, there are three decisions in state chart. The probability of repair willingness is $p$. If $p=1$, the simulation situation is as eq. (6), the user's repair willingness is not under considering.

In the simulation model, we set number of laptop Agents to 1000. The simulation curve of failure Part 1 when broken frequency $n=2$ is shown in Fig. 5. From Fig. 5, we find that simulation curve coincides with theoretical value calculated from eq. (6).

We analysed the significant difference between simulation data and theoretical data. After 30 simulation trials, we list a portion of simulation result in Table V.

When failure frequency $n=2$, the failure parts are 22.73, 18.18, 15.15 in Table V. The simulation means of three failure parts are 21.37, 18.00, and 14.90. The $p$ values (2 tails) are $0.0700,0.7973$, and 0.6623 . All $p$ values are greater than 0.05 . So there is no significant difference between simulation and theoretical value. So eq. (6) is validated.

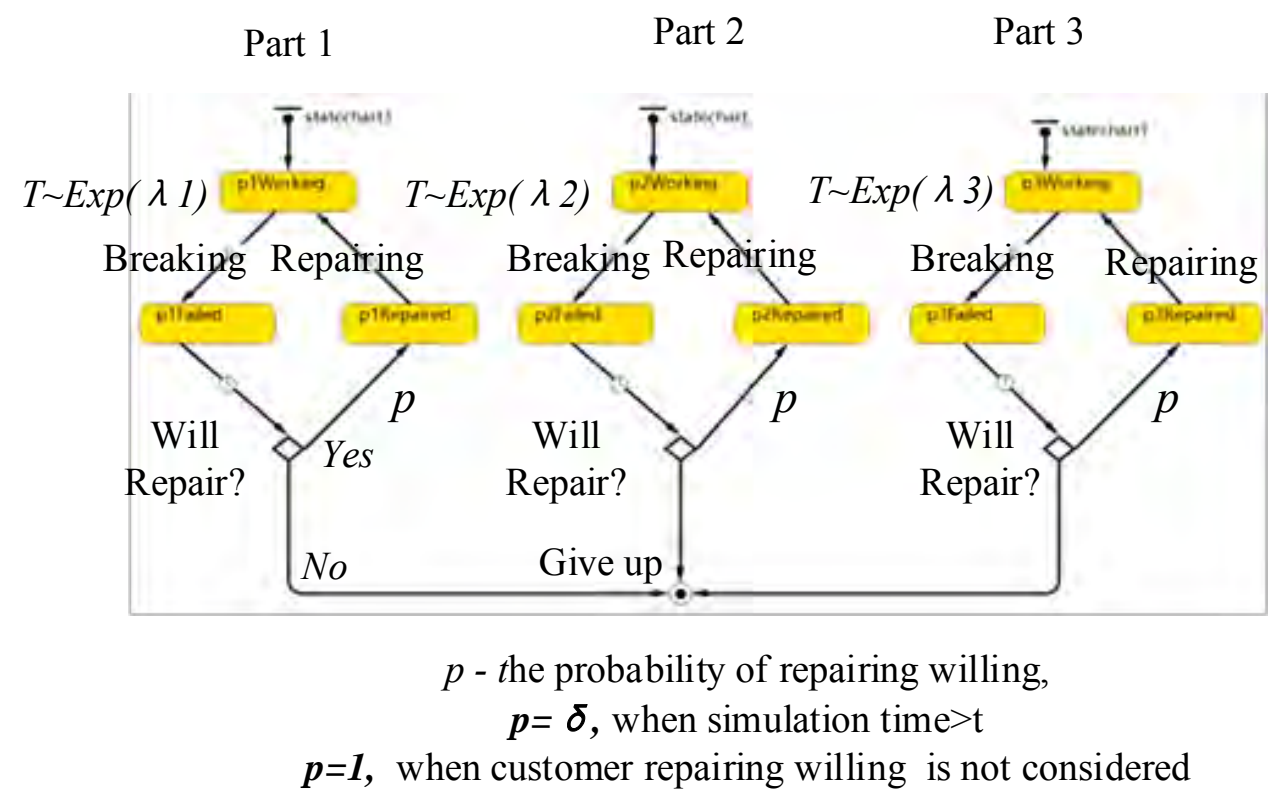

Figure 4: The state chart of simulation model considering users' repair willingness.

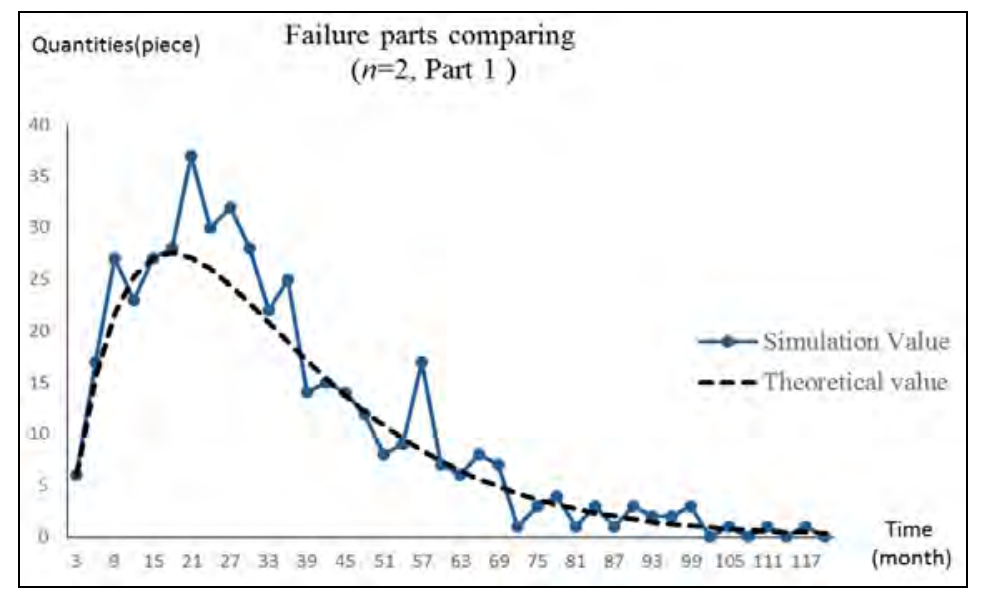

Figure 5: Laptop parts failure quantities simulation result $(n=2$, Part 1).

\subsection{The spare parts model under considering users' repair willingness verification}

The users' repair willingness can influence the demand of laptop spare parts. We verify eq. (8) in this section. 
The simulation model in section 4.1 is also can be applied in this section. Fig. 4 is the state chart of simulation model. In Fig. 4, the user's repair willingness is influenced by failure frequency $p$. When $p=r$, a user will send his laptop to repair with probability $r$. The $r$ value can be looked up in Table I.

Table V: Failure parts quantities simulation significant comparison.

\begin{tabular}{|l|c|c|c|}
\hline \multicolumn{1}{|c|}{ Statistics } & Part 1 & Part 2 & Part 3 \\
\hline Simulation mean & 21.37 & 18.00 & 14.90 \\
\hline Theoretical mean $^{*}$ & 22.73 & 18.18 & 15.15 \\
\hline Std. dev. & 3.97 & 3.89 & 3.14 \\
\hline$t$ value & -1.88 & -0.26 & -0.44 \\
\hline Sig. (two tailed) & 0.07 & 0.80 & 0.66 \\
\hline 95\% conf. & 1.48 & 1.45 & 1.17 \\
\hline Upper bound & 22.85 & 19.45 & 16.07 \\
\hline Lower bound & 19.88 & 16.55 & 13.73 \\
\hline
\end{tabular}

${ }^{*}$ The data is from Table IV, failure frequency $n=2$.

1) The spare parts quantities calculation related to failure frequency

Eq. (8) gives out method to calculate laptop spare parts under certain failure frequency. Because failure frequency in Table II is less than 4 , we think that a laptop owner will give up repairing when failure frequency is over 7 . So we get new users repair willingness probability in Table VI.

Table VI: Modified users' repairing willingness related to failure frequency.

\begin{tabular}{|c|c|c|}
\hline Failure frequency $(\boldsymbol{n})$ & Users' repairing willingness & $\boldsymbol{r}_{\boldsymbol{j}}$ \\
\hline 1 & $100.00 \%$ & $r_{1}$ \\
\hline 2 & $38.64 \%$ & $r_{2}$ \\
\hline 3 & $18.18 \%$ & $r_{3}$ \\
\hline 4 & $3.41 \%$ & $r_{4}$ \\
\hline 5 & $2.27 \%{ }^{*}$ & $r_{5}$ \\
\hline 6 & $1.14 \%{ }^{*}$ & $r_{6}$ \\
\hline 7 & $0.00 \%{ }^{*}$ & $r_{7}$ \\
\hline \multicolumn{2}{|c}{} \\
"Data is interpolation value.
\end{tabular}

By Table III, Table VI and eq. (8), we can get the probability of parts sent to fix under considering users' repairing willingness. When time $t$ is between 27 and 30 months, and failure frequency $n=3$, from eq. (8), we know that the repair willingness $r$ is: $r=r_{1} \cdot r_{2} \cdot r_{3}=$ $1 \times 38.64 \% \times 18.18 \%=7.02 \%$. The failure probability of Part 1 is 0.01996 , shown as Table III (failure frequency $n=3$ ). So the probability of Part 1 be sent to repair is: $0.01996 \times 7.02 \%=$ 0.0014 . Other parts repair probability can be calculated in same way and the result is shown in Table VIII.

If laptops are 1000 sets, we can calculate the quantities of the spare parts of Part 1, Part 2 and Part 3 when the failure frequency $n=1,2,3,4,5,6$. The calculation value is shown in Table IX. (Time $t$ is between 27 and 30 months.) From Table IX, we know that the total demands of spare parts are 23 pcs for Part 1; 18 pcs for Part 2; 15 pcs for Part 3. The quantities are lesser than data in Table IV. It is very important for manufacturers to prepare their spare parts. 
2) Simulation model verification related to failure frequency

Table VIII: Three kinds of parts repairing probability considering failure frequency ( $30 \geq t>27$ months).

\begin{tabular}{|c|c|c|c|}
\hline Failure frequency $(\boldsymbol{n})$ & Part 1 & Part 2 & Part 3 \\
\hline 1 & 0.01295 & 0.01036 & 0.00864 \\
\hline 2 & 0.00878 & 0.00703 & 0.00585 \\
\hline 3 & 0.00140 & 0.00112 & 0.00093 \\
\hline 4 & 0.00003 & 0.00002 & 0.00002 \\
\hline 5 & 0.00000 & 0.00000 & 0.00000 \\
\hline 6 & 0.00000 & 0.00000 & 0.00000 \\
\hline
\end{tabular}

Table IX: The quantities of three kinds of spare parts considering failure frequency ( $30 \geq t>27$ months).

\begin{tabular}{|c|c|c|c|}
\hline Failure frequency $(\boldsymbol{n})$ & Part 1 (pcs) & Part 2 (pcs) & Part 3 (pcs) \\
\hline 1 & 12.95 & 10.36 & 8.64 \\
\hline 2 & 8.78 & 7.03 & 5.85 \\
\hline 3 & 1.40 & 1.12 & 0.93 \\
\hline 4 & 0.03 & 0.02 & 0.02 \\
\hline 5 & 0.00 & 0.00 & 0.00 \\
\hline 6 & 0.00 & 0.00 & 0.00 \\
\hline Total & 23.17 & 18.53 & 15.44 \\
\hline
\end{tabular}

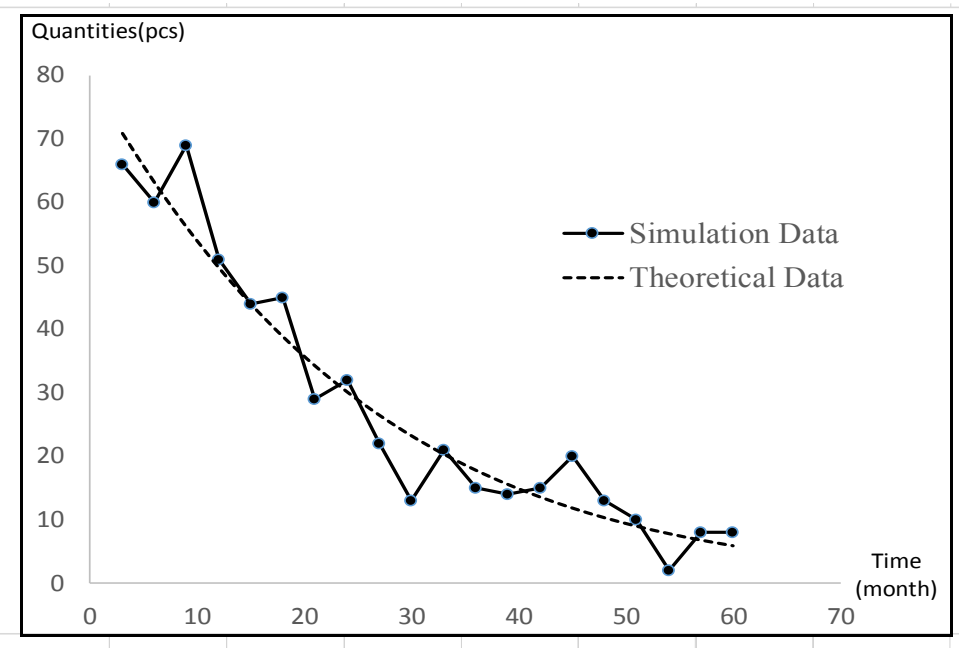

Figure 8: The simulation curve of Part 1 considering failure frequency $(n=1 \sim 7)$.

By simulation model mentioned in 4.2 , we can verify eq. (8) and the theoretical calculation result. The simulation result is shown as Fig. 8. We find the simulation curve fits theoretical value very well.

The Table $\mathrm{X}$ is the significance test of simulation result. All $p$ values in Table $\mathrm{X}$ are greater than 0.05 . So there is no difference between simulation data and theoretical data.

When failure frequency $n=1 \sim 7$ and used time $t$ is from the $27^{\text {th }}$ month to the $30^{\text {th }}$ month, the significance test for spare parts is shown in Table XI. All $p$ values in Table XI are greater than 0.05 . So we think the simulation data fits theoretical data. The eq. (8) is verified. 
Table X: The significance test of simulation data related to failure frequency $(n=3)^{*}$.

\begin{tabular}{|l|c|c|c|}
\hline \multicolumn{1}{|c|}{ Statistics } & Part 1 & Part 2 & Part 3 \\
\hline Simulation mean & 1.3 & 1.09 & 0.97 \\
\hline Std. dev. & 1.176 & 0.996 & 1.00 \\
\hline$d f$ & 100 & 100 & 100 \\
\hline Theoretical mean ${ }^{* *}$ & 1.40 & 1.12 & 0.93 \\
\hline$t$ value & 0.87 & 0.32 & 0.35 \\
\hline Sig. (95 \%, two tailed) & 0.39 & 0.75 & 0.73 \\
\hline
\end{tabular}

$* 30 \geq t>27$, failure frequency $n=3$.

${ }^{* *}$ Data is from Table IX.

Table XI: The significance test of total spare parts related to failure frequency $(n=1 \sim 7)^{*}$.

\begin{tabular}{|c|c|c|c|}
\hline Statistics & Part 1 & Part 2 & Part 3 \\
\hline Simulation mean (total spare parts) & 23.41 & 18.06 & 15.26 \\
\hline Std. dev. & 4.665 & 4.275 & 4.004 \\
\hline$d f$ & 100 & 100 & 100 \\
\hline Theoretical mean (total spare parts) $^{* *}$ & 23.17 & 18.53 & 15.44 \\
\hline$t$ value & 0.52 & 1.11 & 0.46 \\
\hline Sig. (95\%, two tailed) & 0.60 & 0.27 & 0.65 \\
\hline
\end{tabular}

$30 \geq t>27$, failure frequency $n=1 \sim 7$.

${ }^{* *}$ Data is from Table IX.

\section{CONCLUSION}

From discussion, we know when we calculate quantity of laptop spare parts, we can not only consider the laptop life time, but also consider users repair willingness as well. By survey, we know that if a laptop had been broken over 4 times, only $3.4 \%$ users would have their laptops been repaired. This paper gives out approach how to calculate laptop spare parts repairing probability under different failure frequency. The simulation and calculation results confirm each other very well. By comparing Table IV and Table IX, we know that the quantities of spare parts are lower than normal. It is significance for laptop manufacturers. If they can get their parts life time, by eq. (8), they can cut down their spare parts inventory sharply.

\section{ACKNOWLEDGEMENT}

This paper is funded by National Natural Science Foundation of China (Grant No. 71132008, 71390334) and supported by Chinese Railway Corporation research project (2013F029), Beijing Planning Office of Philosophy and Social Science research project (14JDJGB034) as well.

\section{REFERENCES}

[1] Al-Hawari, T.; Ahmed, A.; Khrais, S.; Mumani, A. (2013). Impact of assignment, inventory policies and demand patterns on supply chain performance, International Journal of Simulation Modelling, Vol. 12, No. 3, 164-177, doi:10.2507/IJSIMM12(3)3.235

[2] Buchmeister, B.; Friscic, D.; Lalic, B.; Palcic, I. (2012). Analysis of a three-stage supply chain with level constraints, International Journal of Simulation Modelling. Vol. 11, No. 4, 196-210, doi: $\underline{10.2507 / I J S I M M 11(4) 3.212 ~}$ 
[3] Huiskonen, J. (2001). Maintenance spare parts logistics: Special characteristics and strategic choices, International Journal of Production Economics, Vol. 71, No. 1-3, 125-133, doi:10.1016/ $\underline{\mathrm{S} 0925-5273(00) 00112-2}$

[4] Wong, H.; Cattrysse, D.; Van Oudheusden, D. (2005). Stocking decisions for repairable spare parts pooling in a multi-hub system, International Journal of Production Economics, Vol. 93-94, 309-317, doi:10.1016/j.ijpe.2004.06.029

[5] Cheng, C.-Y.; Prabhu, V. (2012). Evaluation models for service oriented process in spare parts management, Journal of Intelligent Manufacturing, Vol. 23, No. 4, 1403-1417, doi:10.1007/ s10845-010-0486-0

[6] Jin, T.-D.; Tian, Y. (2012). Optimizing reliability and service parts logistics for a time-varying installed base, European Journal of Operational Research, Vol. 218, No. 1, 152-162, doi:10.1016/j.ejor.2011.10.026

[7] Park, C.-W.; Lee, H.-S. (2011). A multi-class closed queueing maintenance network model with a parts inventory system, Computers \& Operations Research, Vol. 38, No. 11, 1584-1595, doi: $10.1016 /$ j.cor.2011.01.020

[8] Bosnjakovic, M. (2010). Multicriteria inventory model for spare parts, Technical Gazette, Vol. 17, No. 4, 499-504

[9] Levner, E.; Perlman, Y.; Cheng, T. C. E.; Levner, I. (2011). A network approach to modeling the multi-echelon spare-part inventory system with backorders and interval-valued demand, International Journal of Production Economics, Vol. 132, No. 1, 43-51, doi:10.1016/ j.ijpe.2011.03.004

[10] Rausch, M.; Liao, H. T. (2010). Joint production and spare part inventory control strategy driven by condition based maintenance, IEEE Transactions on Reliability, Vol. 59, No. 3, 507-516, doi:10.1109/TR.2010.2055917

[11] Wang, W.-B. (2012). A stochastic model for joint spare parts inventory and planned maintenance optimisation, European Journal of Operational Research, Vol. 216, No. 1, 127-139, doi:10.1016/j.ejor.2011.07.031

[12] Basten, R. J. I.; van der Heijden, M. C.; Schutten, J. M. J. (2012). Joint optimization of level of repair analysis and spare parts stocks, European Journal of Operational Research, Vol. 222, No. 3, 474-483, doi:10.1016/j.ejor.2012.05.045

[13] Selcuk, B.; Agrali, S. (2013). Joint spare parts inventory and reliability decisions under a service constraint, Journal of the Operational Research Society, Vol. 64, No. 3, 446-458, doi:10.1057/ jors. 2012.38

[14] Godoy, D. R.; Pascual, R.; Knights, P. (2013). Critical spare parts ordering decisions using conditional reliability and stochastic lead time, Reliability Engineering \& System Safety, Vol. 119, 199-206, doi:10.1016/j.ress.2013.05.026

[15] Louit, D.; Pascual, R.; Jardine, A. (2010). Dynamic optimization model for mining equipment repair by using the spare-parts inventory, Journal of Mining Science, Vol. 46, No. 4, 394-403, doi:10.1007/s10913-010-0049-y

[16] Bacchetti, A.; Saccani, N. (2012). Spare parts classification and demand forecasting for stock control: Investigating the gap between research and practice, Omega, Vol. 40, No. 6, 722-737, doi: 10.1016/j.omega.2011.06.008

[17] Van Horenbeek, A.; Scarf, P. A.; Cavalcante, C. A. V.; Pintelon, L. (2013). The effect of maintenance quality on spare parts inventory for a fleet of assets, IEEE Transactions on Reliability, Vol. 62, No. 3, 596-607, doi:10.1109/TR.2013.2270409

[18] Liu, Q.-M.; Dong, M.; Peng, Y. (2013). A dynamic predictive maintenance model considering spare parts inventory based on hidden semi-Markov model, Proceedings of the Institution of Mechanical Engineers, Part C - Journal of Mechanical Engineering Science, Vol. 227, No. 9, 2090-2103, doi:10.1177/0954406212469773

[19] Sahba, P.; Balcioglu, B. (2011). The impact of transportation delays on repairshop capacity pooling and spare part inventories, European Journal of Operational Research, Vol. 214, No. 3, 674-682, doi:10.1016/j.ejor.2011.05.022

[20] Kleber, R.; Schulz, T.; Voigt, G. (2012). Dynamic buy-back for product recovery in end-of-life spare parts procurement, International Journal of Production Research, Vol. 50. No. 6, 1476-1488, doi: $\underline{10.1080 / 00207543.2011 .560202}$ 
[21] Syntetos, A. A.; Babai, M. Z.; Altay, N. (2012). On the demand distributions of spare parts, International Journal of Production Research, Vol. 50, No. 8, 2101-2117, doi:10.1080/ 00207543.2011 .562561

[22] Sahba, P.; Balcioglu, B.; Banjevic, D. (2103). Spare parts provisioning for multiple $k$-out-of- $n: G$ systems, IIE Transactions, Vol. 45, No. 9, 953-963, doi:10.1080/0740817X.2012.695102

[23] Zhou, C.-X.; Viswanathan, S. (2011). Comparison of a new bootstrapping method with parametric approaches for safety stock determination in service parts inventory systems, International Journal of Production Economics, Vol. 133, No. 1, 481-485, doi:10.1016/ j.ijpe.2010.09.021

[24] Lynch, P.; Adendorff, K.; Yadavalli, V. S. S.; Adetunji, O. (2013). Optimal spares and preventive maintenance frequencies for constrained industrial systems, Computers \& Industrial Engineering, Vol. 65, No. 3, 378-387, doi:10.1016/j.cie.2013.03.005

[25] Eaves, A. H. C.; Kingsman, B. G. (2004). Forecasting for the ordering and stock-holding of spare parts, Journal of the Operational Research Society, Vol. 55, No. 4, 431-437, doi:10.1057/ palgrave.jors. 2601697

[26] Willemain, T. R.; Smart, C. N.; Schwarz, H. F. (2004). A new approach to forecasting intermittent demand for service parts inventories, International Journal of Forecasting, Vol. 20, No. 3, 375-387, doi:10.1016/S0169-2070(03)00013-X

[27] Huang, J.-F.; Zhao, J.-Y.; Wu, X.-D. (2011). Research on the optimization strategy of maintenance spare parts inventory management for petrochemical vehicle, 2011 International Conference on Information Management, Innovation Management and Industrial Engineering (ICIII), 45-48, doi:10.1109/ICIII.2011.18

[28] Li, S. G.; Kuo, X. (2008). The inventory management system for automobile spare parts in a central warehouse, Expert Systems with Applications, Vol. 34, No. 2, 1144-1153, doi:10.1016/ j.eswa.2006.12.003

[29] Kutanoglu, E.; Mahajan, M. (2009). An inventory sharing and allocation method for a multi-location service parts logistics network with time-based service levels, European Journal of Operational Research, Vol. 194, No. 3, 728-742, doi:10.1016/j.ejor.2007.12.032

[30] Gao, J.; Hao, Z. (2012). A classification model for inventory management of spare parts and its application, 2012 International Conference on Industrial Control and Electronics Engineering (ICICEE), 592-595, doi:10.1109/ICICEE.2012.161

[31] Yang, G.-Y.; Dekker, R.; Gabor, A. F.; Axsater, S. (2013). Service parts inventory control with lateral transshipment and pipeline stock flexibility, International Journal of Production Economics, Vol. 142, No. 2, 278-289, doi:10.1016/j.ijpe.2012.11.009

[32] Bertsekas, D. P.; Tsitsiklis, J. N. (2008). Introduction to Probability, $2^{\text {nd }}$ edition, Athena Scientific, Nashua 